\title{
Application of Least Square Approximation Algorithm in the Game Analysis and Data Prediction of the Core Competence Signal of Civil Engineering Employment
}

\author{
Lei Yang ${ }^{1, *}$, Guangxiu Zhou ${ }^{2}$ \\ ${ }^{1}$ School of Economics, Heilongjiang University of Science and Technology, China \\ ${ }^{2}$ School of Accounting, Harbin Finance University, China
}

\begin{abstract}
The least square approximation algorithm is often used to predict the data based on historical experience. In this paper, the method is applied to the research of "game analysis and data prediction of the core competence signal of civil engineering employment", which theoretically verifies the existence of "weak sequence" rational equilibrium in civil engineering employment by means of mathematical reasoning. In addition, the method is applied to the prediction of civil engineering major in one university in Heilongjiang Province from 2010 to 2019 as an example, and the empirical data of employment prove the real existence of the game signal. Finally, according to the method, the research predicts the related data of employment in 2020 .
\end{abstract}

\section{Introduction}

National medium and long-term educational reform and development project summary (2010-2020) pointed out that ordinary colleges and universities should "focus on cultivating high-quality talents and top-notch innovative personnel with persistent faith, excellent moral character, rich knowledge, and strong ability", "support students to participate in scientific research, and strengthen practice teaching links", and "enhance education of employment and enterprising and employment guidance service". Accordingly, colleges and universities in Heilongjiang Province "is gradually transforming and upgrading talent cultivation concept by taking students as the main body and teachers as the leading, and putting efforts on fostering students' social responsibility, spirit of innovation and practical ability". Meanwhile, more attention is given to scientific research projects, an important indicator and main content to measure students' scientific research innovation level.

It is safe to say that students' participation in scientific research projects not only "adapts to objective needs of both the country and social development", but also "abide by the rules of higher education and talent growth". The development of this activity helps "deepen education and teaching reform, innovate education teaching methods, explore various cultivation methods, form a situation that a wealth of talents and top-notch innovative personnel coming out in succession", "cultivate students' scientific innovative level, tamp their major foundation, exercise their practical ability", and "strengthen students' employment competence, enhance their employment quality". In this paper, a game theory model "between students' scientific innovative level and employment ability" is built, and empirical analysis is undertaken by using the data of scientific research projects and employment rate of students in civil engineering of one university in Heilongjiang Province in the past three years, with the expectation that it will bring some guidance effect on the real work ${ }^{[1-3]}$.

\section{Establishment of the game model}

\subsection{Hypothesis of the model}

(1)Client hypothesis: Firstly, two graduates with employment competence of $H$ and $L$ respectively, and $H>L$, and both meet "rational-economic person hypothesis", namely, they will actively choose the company who gives them the highest salary as their employer. Secondly, under the circumstances of market economy, two employers also meet "rational-economic person hypothesis", namely, they would like to hire the graduate with higher employment competence by giving the same lowest salary.

(2)Strategy hypothesis: First, scientific innovation level that the graduates formed in the school is $e$; second, two employers give salary $w_{1}$ and $w_{2}$ after seeing $e$; finally, each graduate chooses one salary (i.e. one employer).

(3)Payment hypothesis: The graduate with employment competence $H$ pays a unit cost of $e / H$ in the process of getting $e$, while the graduate with employment competence $L$ pays a unit cost of $e / L$ in this process. Therefore, profit models of graduates are $w_{1}-e / H$ or $w_{2}-e / H$ and $w_{1}-e / L$ or $w_{2}-e / L$ 
respectively, while that of employers are $H-w_{1}$ or $H-w_{2}$ and $L-w_{1}$ or $L-w_{2}{ }^{[4]}$.

\subsection{Establishment of the model}

It is easy to know that this game theory has a weak sequential equilibrium when analyzing this mentioned hypothesized model through incomplete-information type game theory. Because graduates with employment competence $H$ will enhance his professional innovation level by taking part in various kinds of scientific research activities when he was in university to improve his future employment competitiveness, so as to possess the ability of getting high salary ${ }^{[5-6]}$.

(1)Graduate's strategy: The graduate of Type $H$ is equipped with $e=e^{*}\left(e^{*}>0\right)$, while the graduate of Type $L$ possesses $e=0$, if $w_{1}>w_{2}$, then the graduates of both types all choose employer giving higher salary. If two employers give the same salary, namely $w_{1}=w_{2}$, then the graduates will choose the first company.

(2) Company's strategy: All companies believe that if a graduate choose $e^{*}$, then he is Type $H$, the employer needs to pay him corresponding salary of $H$; otherwise, a graduate chooses $e$, then he is Type $L$, and the employer needs to pay him corresponding salary of $L$.

The following Figure 1 is an "unfolding game theory model of imitating graduates who provide the two employers with their employment competence signal after receiving scientific innovative cultivation and training in university".

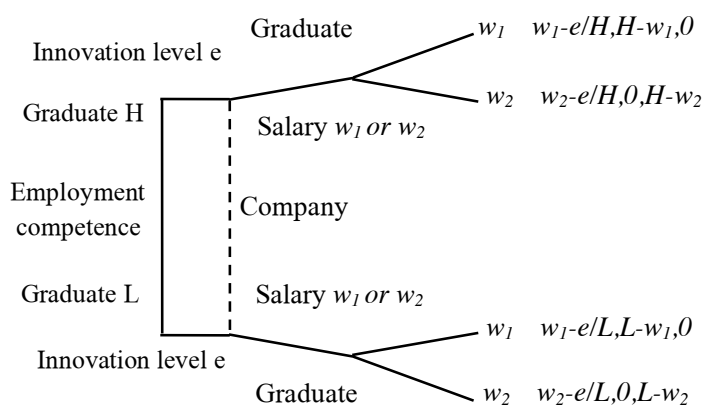

Fig. 1. Simulation of signal game of employment competence

Note: Graduate's strategy and company's strategy in this Figure are compatible, namely, no graduate will choose any other scientific innovation level that is different from $e^{*}$ and 0 , and employers do not impose any restriction when choosing graduates with different employment competences.

\section{Analysis on game model}

Based on the mentioned hypothesis and model establishment, we are going to solve this game theory's "weak sequential" rational equilibrium result.

\subsection{Graduate's action}

Under the assumption of rational-economic person, it is the best strategy for graduates to accept the highest salary offered by employers at the end of the game theory. Now, we are going to think about the graduate's initial action.

(1) Type $H$ graduate: If Type $H$ graduate follows his own strategy and formed scientific innovative level $e^{*}$, then the profit he is going to get is $H-e^{*} / H$; if his formed scientific innovation level is $e$, then the profit is $L-e / H$. Therefore, to get equilibrium, we require $H-e^{*} / H \geq L$, namely, $e^{*} \leq H(H-L)$.

(2) Type $L$ graduate: If Type $L$ graduate follows his own strategy and formed scientific innovation level 0 , then the profit he is going to receive is $L$; if his formed scientific innovation level is $e^{*}$, then employer will believe his employment competence is $H$, and then his profit is $H-e^{*} / L$. Therefore, to get equilibrium, we require $H-e^{*} / L \leq L$, namely, $e^{*} \geq L(H-L)$.

\subsection{Company's action}

Under given strategy, the profit of each employing company is $H-H$ or $L-L$, namely, always 0 . If employer raises his salary offer to respond to graduate's any formed scientific innovation level $e$, then his expected revenue will be negative, and it obviously does not conform to the assumption of rational-economic person; if employer lowers salary offer, his profit is still 0 , because his offer will not be accepted by any graduate.

In conclusion, when and only when

$$
L(H-L) \leq e^{*} \leq H(H-L)
$$

can this game theory have "weak sequential" rational equilibrium result. Again, because we have assumed that $H>L$, through simple mathematical analysis, we can know that $e^{*}$ in this formula does exist. That is to say, to any $H$ and $L$, game theory has separating equilibrium, in which graduate with high employment competence possesses higher scientific innovation level, while graduate with lower employment competence has lower or even has no scientific innovation level. This kind of level has no influence on the graduates' formation of ordinary work ability or production capacity after their entry into work, but the existence of $e^{*}$ means that graduates are equipped with a platform of showing their potentiality, or a chance that shed their possibility of being put in the list of employees with lower capability in the future employer-employee relationship.

\section{Empirical study and data prediction}

In order to further verify the real existence of this game theory model, this paper takes students in civil engineering of one university in Heilongjiang Province as study objects, extracts related data of "students 
participating in scientific research" and "employment rate of overall graduates" of this department from 2010 to 2019 , out of which "high-quality employment rate" and "Fortune 500 employment rate" are taken as a cut-in dot of study, and undertakes analysis and prediction respectively towards the following data in table 1 , table 2 and figure 2 .

\subsection{Empirical study}

\subsubsection{Scientific researches participated by students in civil engineering of one university in the past four years}

Table 1. Number of graduates participating in scientific researches and related employment data contrast from 2010 to 2019 Unit: person

\begin{tabular}{|c|c|c|c|}
\hline \multirow{2}{*}{ Year } & \multirow{2}{*}{$\begin{array}{c}\text { No. of } \\
\text { students in } \\
\text { scientific } \\
\text { researches }\end{array}$} & $\begin{array}{c}\text { No. of high-quality } \\
\text { employment }\end{array}$ & \multirow{2}{*}{ Percentage } \\
\hline & & $\begin{array}{l}\text { No. of working in Fortune } \\
500\end{array}$ & \\
\hline \multirow{2}{*}{2010} & \multirow{2}{*}{67} & \begin{tabular}{|l|}
28 \\
\end{tabular} & $41.79 \%$ \\
\hline & & 16 & $23.88 \%$ \\
\hline \multirow{2}{*}{2011} & \multirow{2}{*}{136} & 59 & $43.38 \%$ \\
\hline & & 32 & $23.53 \%$ \\
\hline \multirow{2}{*}{2012} & \multirow{2}{*}{128} & 56 & $43.75 \%$ \\
\hline & & 32 & $25.00 \%$ \\
\hline \multirow{2}{*}{2013} & \multirow{2}{*}{131} & 59 & $45.04 \%$ \\
\hline & & 34 & $25.95 \%$ \\
\hline \multirow{2}{*}{2014} & \multirow{2}{*}{125} & 56 & $44.80 \%$ \\
\hline & & 35 & $28.00 \%$ \\
\hline \multirow{2}{*}{2015} & \multirow{2}{*}{129} & 60 & $46.51 \%$ \\
\hline & & 37 & $28.68 \%$ \\
\hline \multirow{2}{*}{2016} & \multirow{2}{*}{72} & 34 & $46.58 \%$ \\
\hline & & 21 & $29.17 \%$ \\
\hline \multirow{2}{*}{2017} & \multirow{2}{*}{96} & 53 & $55.21 \%$ \\
\hline & & 36 & $37.50 \%$ \\
\hline \multirow{2}{*}{2018} & \multirow{2}{*}{117} & 83 & $70.94 \%$ \\
\hline & & 49 & $41.88 \%$ \\
\hline \multirow{2}{*}{2019} & \multirow{2}{*}{112} & 81 & $72.32 \%$ \\
\hline & & 57 & $50.89 \%$ \\
\hline
\end{tabular}

Note: Fortune 500 enterprises list is based on the data published by Fortune China, while high-quality employment includes employment in China Top 500, Heilongjiang Top 100 and enrollment as a postgraduate, soldier, civil servant or worker in public institutions.

\subsubsection{Related employment data of students in civil engineering of one university in the past four years}

Table 2. Graduate's overall employment and related employment data contrast from 2010 to 2019 Unit: person

\begin{tabular}{|c|c|c|c|c|c|}
\hline \multirow{2}{*}{ Year } & \multirow{2}{*}{$\begin{array}{c}\text { No. of } \\
\text { graduat } \\
\text { es }\end{array}$} & \multirow{2}{*}{$\begin{array}{c}\text { No. of } \\
\text { employ } \\
\text { ment }\end{array}$} & \multirow{2}{*}{$\begin{array}{c}\text { Employ } \\
\text { ment } \\
\text { rate }\end{array}$} & $\begin{array}{l}\text { No. of high- } \\
\text { quality } \\
\text { employment }\end{array}$ & \multirow{2}{*}{ Percentage } \\
\hline & & & & $\begin{array}{c}\text { No. of } \\
\text { working in } \\
\text { Fortune } 500\end{array}$ & \\
\hline \multirow{2}{*}{2010} & \multirow{2}{*}{475} & \multirow{2}{*}{455} & \multirow{2}{*}{$95.79 \%$} & 152 & $32.00 \%$ \\
\hline & & & & 72 & $15.16 \%$ \\
\hline \multirow{2}{*}{2011} & \multirow{2}{*}{637} & \multirow{2}{*}{618} & \multirow{2}{*}{$97.02 \%$} & 217 & $34.07 \%$ \\
\hline & & & & 115 & $18.05 \%$ \\
\hline \multirow{2}{*}{2012} & \multirow{2}{*}{602} & \multirow{2}{*}{576} & \multirow{2}{*}{$95.68 \%$} & 199 & $33.06 \%$ \\
\hline & & & & 128 & $21.26 \%$ \\
\hline \multirow{2}{*}{2013} & \multirow{2}{*}{605} & \multirow{2}{*}{570} & \multirow{2}{*}{$94.21 \%$} & 203 & $33.55 \%$ \\
\hline & & & & 124 & $20.00 \%$ \\
\hline \multirow{2}{*}{2014} & \multirow{2}{*}{598} & \multirow{2}{*}{572} & \multirow{2}{*}{$95.65 \%$} & 217 & $36.29 \%$ \\
\hline & & & & 103 & $17.22 \%$ \\
\hline & & & & & \\
\hline \multirow{2}{*}{2015} & \multirow{2}{*}{689} & \multirow{2}{*}{637} & \multirow{2}{*}{$92.45 \%$} & 237 & $34.40 \%$ \\
\hline & & & & 113 & $16.40 \%$ \\
\hline \multirow{2}{*}{2016} & \multirow{2}{*}{632} & \multirow{2}{*}{601} & \multirow{2}{*}{$95.09 \%$} & 207 & $32.75 \%$ \\
\hline & & & & 81 & $12.82 \%$ \\
\hline \multirow{2}{*}{2017} & \multirow{2}{*}{475} & & & 167 & $35.16 \%$ \\
\hline & & 455 & $95.79 \%$ & 43 & $9.05 \%$ \\
\hline 2018 & 637 & 618 & $0700 \%$ & 323 & $50.71 \%$ \\
\hline 2018 & & 018 & $91.02 \%$ & 186 & $29.20 \%$ \\
\hline & & & & 309 & $51.33 \%$ \\
\hline 2019 & 602 & 576 & $95.68 \%$ & 168 & $27.91 \%$ \\
\hline
\end{tabular}

\subsubsection{Data contrast and analysis}

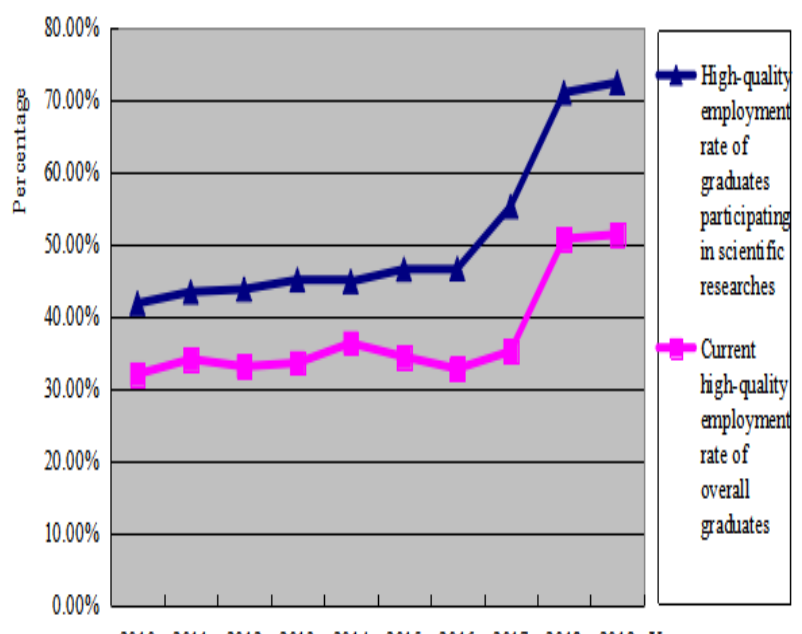

2010201120122013201420152016201720182019 Year

Fig. 2. Comparison of employment quality between two types of students

(1)Data in Table 1 and Table 2 indicate that from 2010 to 2019, high-quality employment rate of students in civil engineering of one university in Heilongjiang Province, whether the employment rate of graduates in scientific research or that of overall graduates, this index has been increasing year by year on the whole; percentage and growth scale of "high-quality employment rate of students participating in scientific 
research" are much higher than current corresponding indexes. Data contrast is shown in Figure 2.

(2)When analyzing graduates' "Fortune 500 employment rate", we find out that this index from 2013 to 2017 decreased compared with that in the previous year. Exterior elements that influence employment caused the slide of this index include the downturn of domestic real estate market, the shrunk of construction engineering market, the slowdown of infrastructure investment, etc. However, "Fortune 500 employment rate" of students taking part in scientific research of those years still kept strong growth. Data contrast is shown in Figure 2.

\subsection{Data prediction}

Mathematical algorithm of "Least Squares Approximations" $y=a+b x$, out of which $a=\frac{\sum y_{i}-b\left(\sum x_{i}\right)}{n}, \quad b=\frac{\left(\sum x_{i}\right)\left(\sum y_{i}\right)-n\left(\sum x_{i} y_{i}\right)}{\left(\sum x_{i}\right)^{2}-n\left(\sum x_{i}^{2}\right)}$ is used to predict two data of "overall high-quality employment rate" and "high-quality employment rate of students participating in scientific research" of students in civil engineering major of one university in Heilongjiang Province in 2020. Details are as followed in Table 3 and Table 4.

\subsubsection{Prediction on high-quality employment rate of graduates participating in scientific researches in 2020}

Table 3. Calculation of related data of students participating in scientific researches from 2010 to 2019 Unit: percentage

\begin{tabular}{cccc}
\hline$x_{i}$ & $y_{i}$ & $x_{i}{ }^{2}$ & $x_{i} y_{i}$ \\
\hline 1 & $41.79 \%$ & 1 & $41.79 \%$ \\
\hline 2 & $43.38 \%$ & 4 & $86.76 \%$ \\
\hline 3 & $43.75 \%$ & 9 & $131.25 \%$ \\
\hline 4 & $45.04 \%$ & 16 & $180.16 \%$ \\
\hline 5 & $44.80 \%$ & 25 & $224.00 \%$ \\
\hline 6 & $46.51 \%$ & 36 & $279.06 \%$ \\
\hline 7 & $46.58 \%$ & 49 & $326.06 \%$ \\
\hline 8 & $55.21 \%$ & 64 & $441.68 \%$ \\
\hline 9 & $70.94 \%$ & 81 & $638.46 \%$ \\
\hline 10 & $72.32 \%$ & 100 & $723.20 \%$ \\
\hline
\end{tabular}

Note: $\sum x_{i}=55 ; \sum y_{i}=510.32 \% ; \sum x_{i}{ }^{2}=385 ; \sum x_{i} y_{i}=3072.42 \%$

Result: from Table 3, we can get the following result.

$$
\begin{gathered}
b=\frac{\left(\sum x_{i}\right)\left(\sum y_{i}\right)-n\left(\sum x_{i} y_{i}\right)}{\left(\sum x_{i}\right)^{2}-n\left(\sum x_{i}^{2}\right)}=\frac{(55 \times 510.32 \%)-(10 \times 3072.42 \%)}{55^{2}-(10 \times 385)}=3.22 \% \\
a=\frac{\sum y_{i}-b\left(\sum x_{i}\right)}{n}=\frac{510.32 \%-(3.22 \% \times 55)}{10}=33.32 \% \\
y=a+b x=33.32 \%+3.22 \% \times 11=68.74 \%
\end{gathered}
$$

That is to say, the predicting data of high-quality employment rate of graduates participating in scientific researches in 2020 is $68.74 \%$.

\subsection{Prediction on high-quality employment rate of overall graduates in 2020}

Table 4. Calculation on related data of overall graduates' employment from 2010 to 2019 Unit: percentage

\begin{tabular}{cccc}
\hline$x_{i}$ & $y_{i}$ & $x_{i}{ }^{2}$ & $x_{i} y_{i}$ \\
\hline 1 & $32.00 \%$ & 1 & $32.00 \%$ \\
\hline 2 & $34.07 \%$ & 4 & $68.14 \%$ \\
\hline 3 & $33.06 \%$ & 9 & $99.18 \%$ \\
\hline 4 & $33.55 \%$ & 16 & $134.20 \%$ \\
\hline 5 & $36.29 \%$ & 25 & $181.45 \%$ \\
\hline 6 & $34.40 \%$ & 36 & $206.40 \%$ \\
\hline 7 & $32.75 \%$ & 49 & $229.25 \%$ \\
\hline 8 & $35.16 \%$ & 64 & $281.28 \%$ \\
\hline 9 & $50.71 \%$ & 81 & $456.39 \%$ \\
\hline 10 & $51.33 \%$ & 100 & $513.30 \%$ \\
\hline
\end{tabular}

Note: $\sum x_{i}=55 ; \sum y_{i}=373.32 \% ; \sum x_{i}{ }^{2}=385 ; \sum x_{i} y_{i}=2201.59 \%$

Result: we can get the following result from Table 4.

$$
\begin{gathered}
b=\frac{\left(\sum x_{i}\right)\left(\sum y_{i}\right)-n\left(\sum x_{i} y_{i}\right)}{\left(\sum x_{i}\right)^{2}-n\left(\sum x_{i}^{2}\right)}=\frac{(55 \times 373.32 \%)-(10 \times 2201.59 \%)}{55^{2}-(10 \times 385)}=1.79 \% \\
a=\frac{\sum y_{i}-b\left(\sum x_{i}\right)}{n}=\frac{373.32 \%-(1.79 \% \times 55)}{10}=27.49 \% \\
y=a+b x=27.49 \%+1.79 \% \times 11=47.18 \%
\end{gathered}
$$

That is to say, the predicting data of overall graduates' high-quality employment rate in 2020 is $47.18 \%$

\section{Conclusion}

Firstly, based on the least square approximation algorithm and historical empirical data, taking the civil engineering major of this university as an example, the predicting data of high-quality employment rate of graduates participating in scientific researches and overall graduates' high-quality employment rate in 2020 are $68.74 \%$ and $47.18 \%$ respectively. Secondly, the condition for math algorithm's establishment is that the proportion of graduates participating in scientific research shows a weak linear growth trend year by year on the whole. Thirdly, only when the "high quality employment rate of graduates participating in scientific research" in the previous years reaches the value listed in the table, can the forecast value of "overall high quality employment rate of graduates" in this year be calculated.That is to say, "weak sequential" rational equilibrium exists between these two items. Fourthly, this prediction algorithm is only a theoretical one. Real employment and formation of related data are still influenced by various kinds of interior and exterior elements.

\section{References}

1. Bernhard Rengs, Manuel Scholz-Wäckerle, Jeroen van den Bergh. Evolutionary macroeconomic assessment of employment and innovation impacts 
of climate policy packages. Journal of Economic Behavior and Organization,2019(12):1-16.

2. Wang Dong. Study on the transformation and innovation teaching mode of university political education under internet plus era background. Technical Bulletin,2017(15):385-391.

3. Fan Junjie, Zhang Chunli, Zhang Jiutao, Wu Yueda. A multi-dimensional innovation approach for college students political education based on computer cloud data platform. Technical Bulletin,2017(15):740-746.

4. Martin J Osborne, translated by Xiquan Shi, etc. An introduction to game theory. Shanghai: Shanghai Financial University Press,2010:319-321.

5. Lei Yang, Chengbin Wu. Game theory on the level of students' scientific research innovation as employment competences signal — taking the employment of civil engineering students in a university in Heilongjiang Province as an example, Economist, 2012(1):113-114.

6. Chengbin $\mathrm{Wu}$, Lei Yang. Research on the cultivation of College Students' innovation consciousness and employment ability,Journal of Northeast Agricultural University(Social Sciences),2012(12):41-42. 